\title{
Quantitative Assessment of Vertical and Horizontal Deformations Derived by 3D and 2D Decompositions of InSAR Line-of-Sight Measurements to Supplement Industry Surveillance Programs in the Tengiz Oilfield (Kazakhstan)
}

\author{
Emil Bayramov ${ }^{1,2, *}$, Manfred Buchroithner ${ }^{3} \mathbb{D}$, Martin Kada ${ }^{2}$ and Yermukhan Zhuniskenov ${ }^{1}$ \\ 1 School of Mining and Geosciences, Nazarbayev University, 53 Kabanbay Batyr Ave, \\ Nur-Sultan 010000, Kazakhstan; yermukhan.zhuniskenov@nu.edu.kz \\ 2 Methods of Geoinformation Science, Institute of Geodesy and Geoinformation Science, \\ Technical University of Berlin, 10623 Berlin, Germany; martin.kada@tu-berlin.de \\ 3 Institute of Cartography, Helmholtzstr. 10, 01069 Dresden, Germany; manfred.buchroithner@tu-dresden.de \\ * Correspondence: emil.bayramov@nu.edu.kz
}

check for updates

Citation: Bayramov, E.; Buchroithner, M.; Kada, M.; Zhuniskenov, Y. Quantitative Assessment of Vertical and Horizontal Deformations Derived by 3D and 2D Decompositions of InSAR Line-of-Sight Measurements to Supplement Industry Surveillance Programs in the Tengiz Oilfield (Kazakhstan). Remote Sens. 2021, 13, 2579. https://doi.org/10.3390/ rs13132579

Academic Editor: Alex Hay-Man Ng

Received: 1 June 2021

Accepted: 25 June 2021

Published: 1 July 2021

Publisher's Note: MDPI stays neutral with regard to jurisdictional claims in published maps and institutional affiliations.

Copyright: (c) 2021 by the authors. Licensee MDPI, Basel, Switzerland. This article is an open access article distributed under the terms and conditions of the Creative Commons Attribution (CC BY) license (https:// creativecommons.org/licenses/by/ $4.0 /)$.

\begin{abstract}
This research focused on the quantitative assessment of the surface deformation velocities and rates and their natural and man-made controlling factors at Tengiz Oilfield in Kazakhstan using the Small Baseline Subset remote sensing technique followed by 3D and 2D decompositions and cosine corrections to derive vertical and horizontal movements from line-of-sight (LOS) measurements. In the present research we applied time-series of Sentinel-1 satellite images acquired during 2018-2020. All ground deformation derivatives showed the continuous subsidence at the Tengiz oilfield with increasing velocity. 3D and 2D decompositions of LOS measurements to vertical movement showed that the Tengiz Oil Field 2018-2020 continuously subsided with the maximum annual vertical deformation velocity around $70 \mathrm{~mm}$. Based on the LOS measurements, the maximum annual subsiding velocity was observed to be $60 \mathrm{~mm}$. Cosine corrections of LOS measurements to vertical movement, however, revealed a maximum annual vertical deformation velocity of $77 \mathrm{~mm}$. The vertical deformation confirmed typical patterns of subsidence caused by oil extraction. Detected east-west and north-south horizontal movements at the Tengiz field clearly indicated that the study area crossed by seismic faults is affected by natural tectonic processes. The overall RMSE of 3D decomposed vertical deformation in relationship to LOS measurements and cosine corrections were in the range of 10-13 $\mathrm{mm}$ and 6-8 $\mathrm{mm}$, correspondingly. The results of the present research will support operators of oil and gas fields and also other types of infrastructure to evaluate the actual differences of InSAR ground deformation measurements against the required standards and the precision of measurements depending on the operational needs, timeframes and availability of radar imagery.
\end{abstract}

Keywords: SBAS; 2D and 3D decomposition; remote sensing; geospatial; oil field; radar; interferometry

\section{Introduction}

Tengiz is an oilfield located in NW Kazakhstan's low-lying wetlands along the northeast shores of the Caspian Sea. Recent studies by Grebby et al. [1] and Orynbassarova [2] proved that Tengiz Field has been for some time under the long-term influence of subsidence induced by oil and gas production.

Monitoring of ground deformation processes at oil and gas fields has several business values for industry since it is one of the critical input parameters for geohazard risk assessment, induced seismicity, geomechanics surveillance programs (reservoir stress, volumetric strain, fault reactivations and dislocation), site safety for fault or landslide reactivation, well failures, environmental assessment, reservoir modelling, enhanced oil recovery (EOR), oil and gas production. 
Interferometric Synthetic Aperture Radar (InSAR) technology was verified as a more effective technology for the ground deformation monitoring of large oil and gas fields and their infrastructure rather than traditional geodetic measurements of single points [3-6]. Even though geodetic measurements have higher accuracy, they do not reflect the large scale of deformation patterns [7].

Grebby et al. [1] and Orynbassarova [2] examined ground deformation characteristics caused by oil and gas exploitation in this area for the period of 2004-2009 and 20162017, by using Envisat ASAR and Sentinel-1 satellite images, respectively. The studies by Grebby et al. [1] and Orynbassarova [2] used the Intermittent Small Baseline Subset (ISBAS) technique that allowed them to determine the significant evolution of deformation over the Tengiz field in 2016-2017, with subsidence increasing dramatically to a maximum of $-79.3 \mathrm{~mm}$ /year. Moreover, the studies by Grebby et al. [1] and Orynbassarova [2] demonstrated the benefits of the ISBAS technique to increase the density of ground deformation measurements. Comola et al. [8] and Del Conte et al. [9] used the SqueeSAR method for the global optimization of reservoir geomechanical parameters based on SAR-derived ground displacements for the period of 2004-2007 using the ascending geometry of Radarsat-1 satellite images. The studies by Comola et al. [8] demonstrated that the coupling of surface deformation monitoring and geo-mechanical modelling was a powerful tool to characterize hydrocarbon reservoirs during their production life. Katrenov et al. [10] studied the impact of reservoir pressure depletion on reservoir compaction and surface subsidence. Zhantaev et al. [11] used the SBAS technique to monitor ground deformation at the Tengiz field using ENVISAT 2004-2009 and ALOS PALSAR 2007-2010 satellite images. All of the foregoing studies demonstrated the presence of subsidence processes induced by oil production in the Tengiz field.

Zhantayev et al. [12] also used the persistent scatterers interferometry technique for urban subsidence monitoring in the Republic of Kazakhstan. These studies [12] applied COSMO-SkyMed 2011-2013 for Nur-Sultan City and ENVISAT ASAR 2003-2006 radar satellite images for Almaty City. InSAR was also used for other oil and gas fields and mining sites in Kazakhstan like the the Karazhanbas oilfield, etc. $[13,14]$ and the undermined Karaganda coal basin [15].

However, there have been few publicly accessible studies on the surface deformation characteristics of the Tengiz field in recent years. Therefore, monitoring recent surface deformations over the Tengiz oilfield is of great importance and business value for guiding the continued exploitation there. To the extent of our knowledge, there are also no publicly accessible studies focused on the use of 3D or 2D decomposition techniques to derive vertical and horizontal deformations for the Tengiz field in the recent years. The present studies thus offer practical scientific value and advantages for the petroleum and gas industry. Preliminary understanding of differences in ground deformation measurements using single- and multi-track radar images would help petroleum and gas operators to select a suitable methodology depending on the required organizational standards for a certain precision and reliability.

It is well known that time-series InSAR analysis enable measuring surface motions with millimeter to centimeter precision. However, there is a limitation of InSAR that the resulting motion measurements from a single track are restricted to a LOS viewing geometry. Since ground deformation processes generally occur in three spatial dimensions (east, north and up), many studies have used both descending and ascending tracks to enable assessment of actual vertical and horizontal displacements [16-19].

Our research focused on the quantitative assessment of the surface deformation velocities and rates and their natural and man-made controlling factors at the Tengiz oilfield using Small Baseline Subset (SBAS) remote sensing and geostatistical interpolation techniques followed by 3D and 2D decompositions and cosine corrections to derive vertical and horizontal movements from LOS measurements. According to Even et al. [20], 2D and $3 \mathrm{D}$ displacements in vertical, east-west and north-south directions derived from InSAR LOS measurements holds a fundamental role for the integrated analysis and integration 
with other data of oil and gas reservoirs. A number of successful InSAR studies applied 3D and 2D decompositions and cosine corrections techniques to derive vertical and horizontal deformations for oil and gas fields $[1,21,22]$. The present research specifically focused on the comparative aspects of LOS measurements with the consequently derived vertical and horizontal deformations from 3D and 2D decompositions and cosine corrections in the Tengiz oilfield for the period of 2018-2020.

Sentinel-1 satellite images acquired from ascending and descending tracks during 2018-2020 were used in our studies. The primary advantage of the present research will be to examine the differences in vertical deformation measurements using both descending and ascending tracks and also to assess the horizontal movements for the recent years. The detailed research goals are as follows:

(1) Determination of ground deformation velocities and rates at the Tengiz oilfield over the period of 2018-2020 using SBAS remote sensing techniques followed by 3D and $2 \mathrm{D}$ decompositions and cosine corrections to derive vertical and horizontal east-west and north-south movements from LOS measurements

(2) Detection of vertical and horizontal ground deformation hotspots

(3) Quantitative comparison of the ground deformation velocities and rates derived from LOS, 3D and 2D decomposition and cosine correction measurements

(4) Assessment of the spatial relationships between the detected patterns of vertical and horizontal ground deformations, man-made oil field exploitation and natural tectonic processes

(5) Provision of recommendations to operators of oil and gas fields and other types of petroleum infrastructure.

\section{Materials and Methods}

\subsection{Study Area}

The Tengiz oilfield was discovered in 1979 and it is one of the largest discoveries worldwide in recent history. It is located in northwestern Kazakhstan's low-lying wetlands along the northeast shores of the Caspian Sea (Figure 1a-c) and covers an area of $430 \mathrm{~km}^{2}$, being $19 \mathrm{~km}$ wide and $21 \mathrm{~km}$ long. It is located $150 \mathrm{~km}$ south-east of the city of Atyrau which is considered to be the main transport hub for Tengiz oil. The Tengiz field has recoverable reserves estimated at between six billion and nine billion barrels. However, the reservoir is estimated to contain around 25 billion barrels of oil and is located at the depth of 3885-5117 $\mathrm{m} \mathrm{[1].} \mathrm{The} \mathrm{oil} \mathrm{comes} \mathrm{out} \mathrm{of} \mathrm{wells} \mathrm{hot} \mathrm{at} \mathrm{high} \mathrm{pressure} \mathrm{and} \mathrm{with} \mathrm{a} \mathrm{large}$ proportion of gas. Current oil production is 720,000 barrels per day. The region has a semi-arid climate, with temperatures decreasing to $-30{ }^{\circ} \mathrm{C}$ in winter and reaching up to $40^{\circ} \mathrm{C}$ in summer. The average annual precipitation varies in the range of 100-200 $\mathrm{mm}$ [23]. As shown in Figure 1b, the terrain of the study area is flat, but with regular depressions formed as a result of seasonal snow melts and rainfalls [1]. The sour gas injection enhanced oil recovery method is used at the Tengiz oilfield [24]. The Tengiz field is located within the seismically active region of Kazakhstan [25]. Existing faulting and erosion at the Tengiz field suggest the possible gravity-driven mass movement of carbonate rocks [26]. Besides the primary man-made oil production factor, the subsidence processes at the Tengiz field are seemingly bound by northwest-southeast trending faults $[1,26]$. 


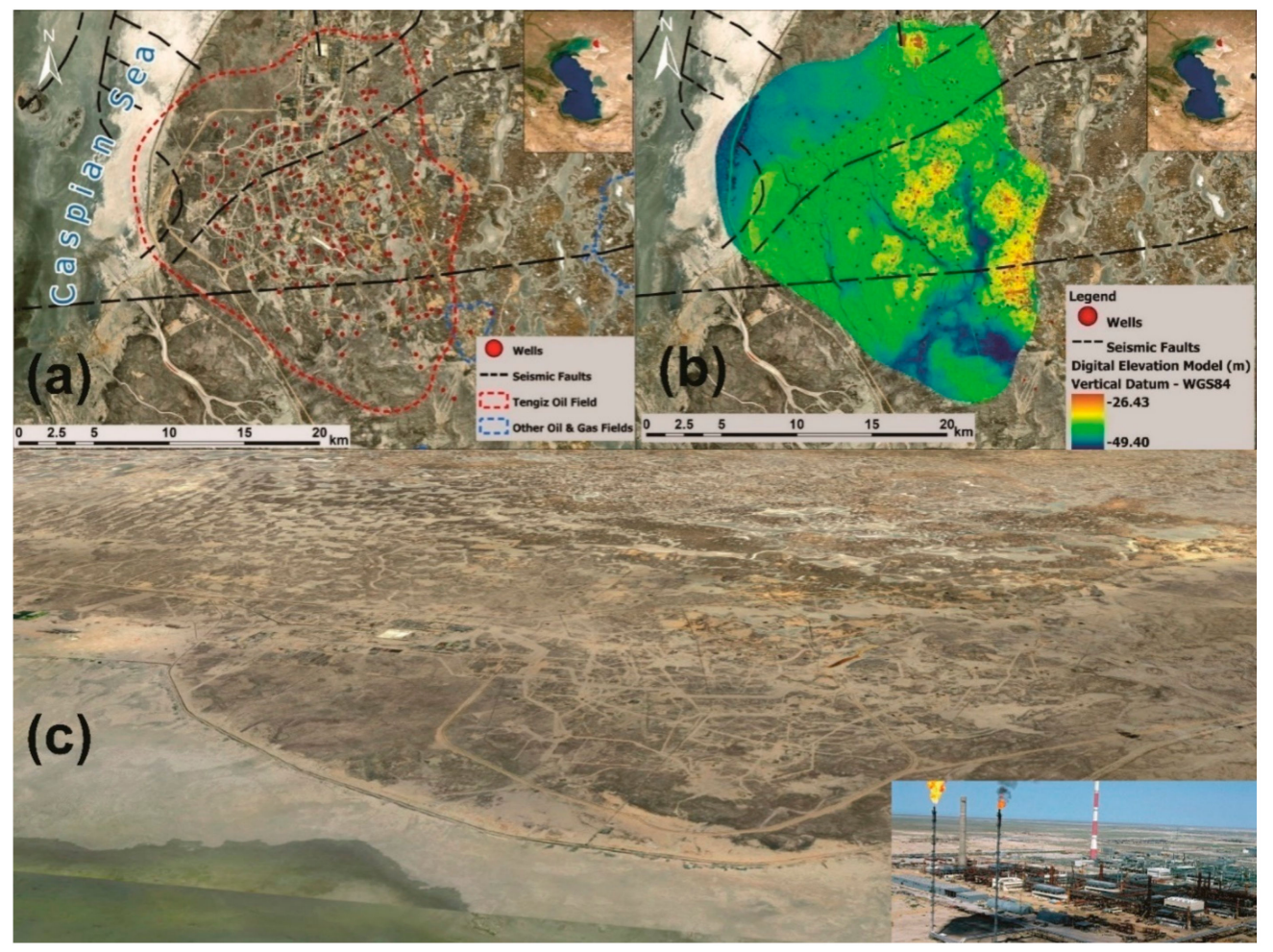

Figure 1. (a) Tengiz oilfield with the representation of wells; (b) Elevation model of the Tengiz oilfield; (c) Oblique aerial view of the Tengiz field.

\subsection{Quantitative Assessment of Ground Deformations at the Tengiz Oilfield Using SBAS} Techniques, 3D \& 2D Decompositions and Cosine Corrections

C-band $(5.6 \mathrm{~cm}$ wavelength and $5.4 \mathrm{GHz})$ Sentinel-1 A/B TOPS images from the European Space Agency (ESA) were used for the present research to map the spatial distribution and rates of ground deformation at the Tengiz oilfield.

89 images were acquired on ascending Path 57, Frame 148, Absolute Orbit 30579, with VV + VH Polarization between 1 January 2018 and 31 December 2020 (Figure 2a). 85 images were acquired on ascending Path 159, Frame 149, Absolute Orbit 35931, with VV + VH Polarization between 1 January 2018 and 31 December 2020 (Figure 2a). 96 images were acquired on descending Path 35, Frame 441, Absolute Orbit 30557, with VV + VH Polarization between 1 January 2018 and 31 December 2020 (Figure 2a). Sentinel-1 VV polarization bands were used since co-polarized bands provide higher coherence [27]. The study area was fully covered by all three tracks. Sentinel-1 images in wide-swath mode provide a wide coverage of about $250 \mathrm{~km}$ with a slant range resolution of $5 \mathrm{~m}$ and an azimuth resolution of $20 \mathrm{~m}$ [28]. The connection graphs of SAR images in Figure 2b,c show that all radar images were well connected in time in order to follow the displacement monitoring over the period of 2018-2020. The interferometric processing was performed using the Small Baseline Subset (SBAS) technique followed by 3D and 2D decompositions, cosine corrections and geospatial analysis to derive both vertical and horizontal deformations. The SBAS workflow in Figure 3 was used for the following research steps: creation of a connection graph, generation of interferogram, Goldstein interferogram filtering, orbital refinement and reflattening, removal of atmospheric and topographic errors, phase unwrapping, and phase-to- displacement conversion [29]. The topographic contribution to the radar phase was corrected using the Shuttle Radar Topography Mission (SRTM) 1 arcsecond digital elevation model (DEM) with $30 \mathrm{~m}$ spatial resolution [30]. It is well known that SAR interferometry can measure only one dimension of the LOS surface deformation [31]. Therefore for these studies both ascending and descending tracks of Sentinel-1 images were used to decompose the produced LOS velocity fields into the horizontal component along the azimuth look direction $d_{h o r}$ and the vertical component $d_{v e r}$ taking into 
account the local incidence angle of the satellite view by the following 2D decomposition Equation (1) [18,32-37]:

$$
\left(\begin{array}{c}
d_{L O S}^{a s c} \\
d_{L O S}^{d s c}
\end{array}\right)=\left(\begin{array}{c}
\cos \theta_{\mathrm{asc}}-\cos \alpha_{\mathrm{asc}} \sin \theta_{a s c} \\
\cos \theta_{d s c}-\cos \alpha_{\mathrm{dsc}} \sin \theta_{d s c}
\end{array}\right)\left(\begin{array}{c}
d_{\text {ver }}(\text { Up }- \text { Down }) \\
d_{\text {hor (East-West })}
\end{array}\right)
$$

where $\theta_{a s c}$ and $\theta_{d s c}$ are the local incidence angles and $\alpha_{a s c}$ and $\alpha_{d s c}$ are the satellite heading angles of ascending and descending modes [32,38].

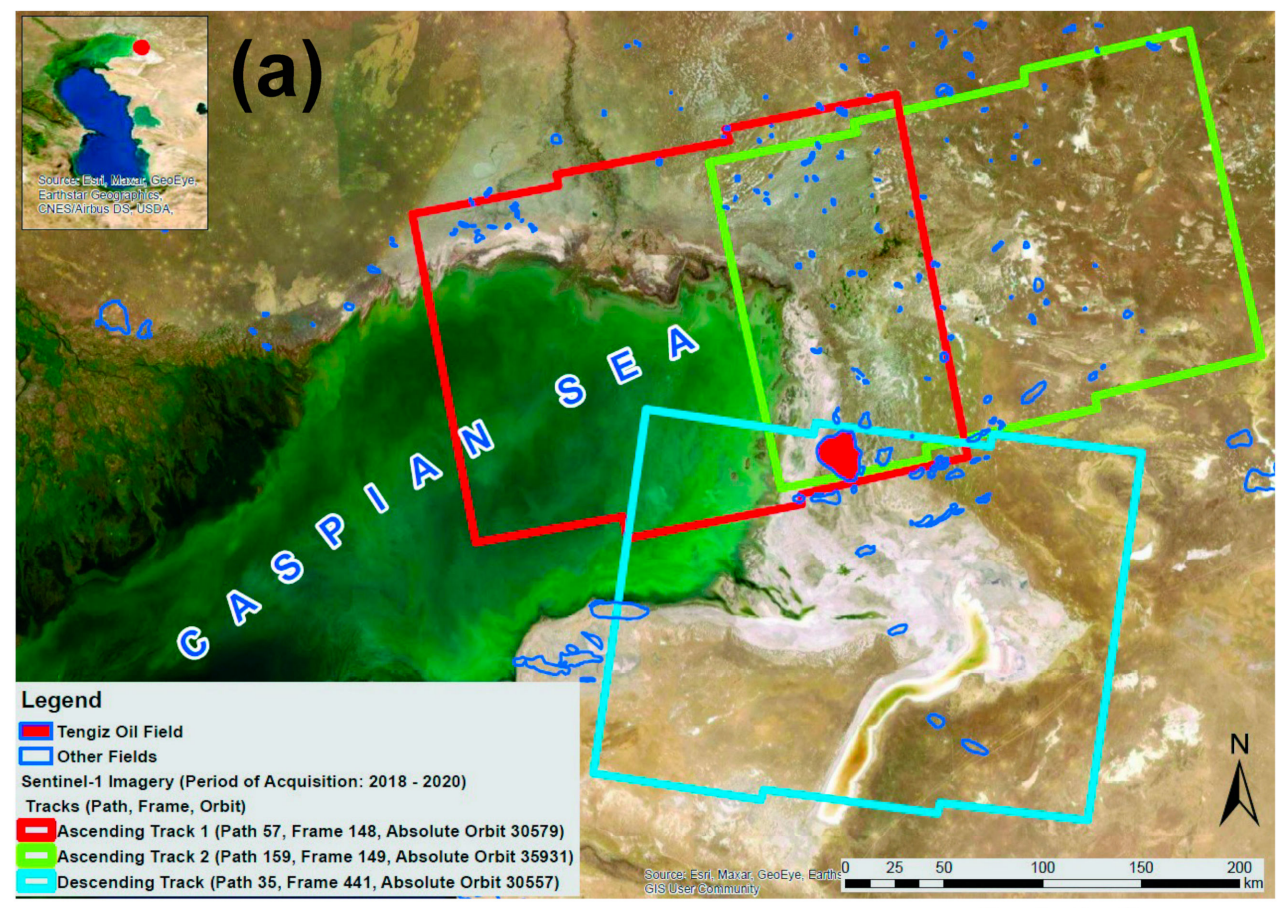

Time-Baseline Plo
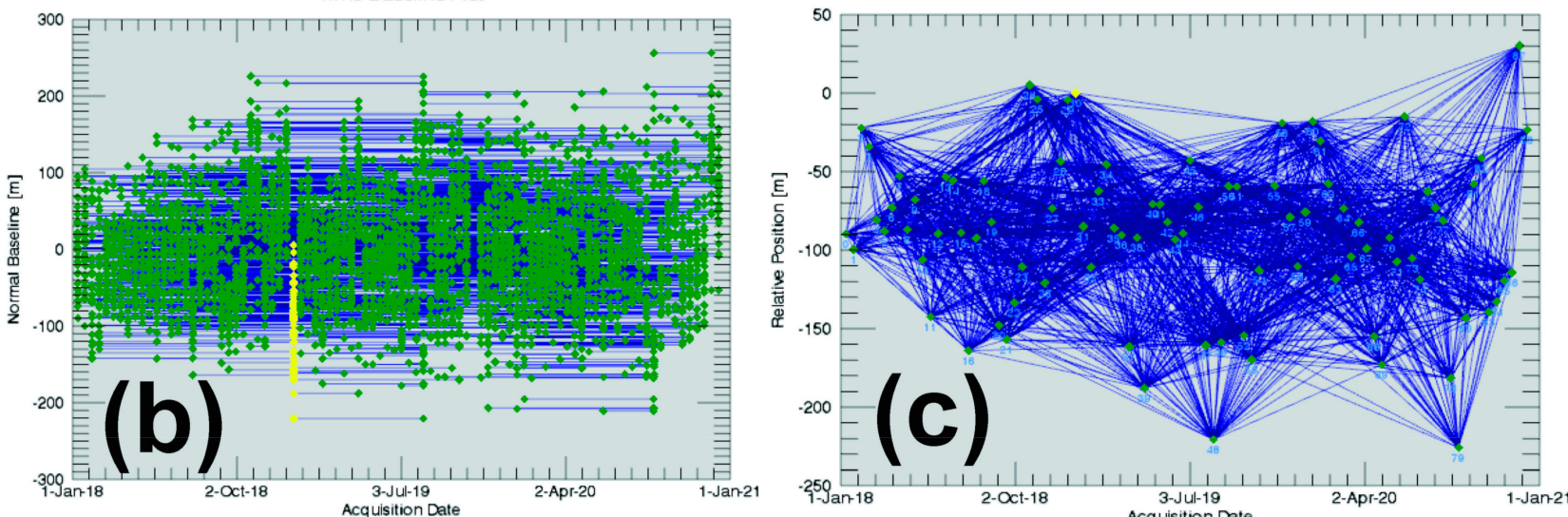

Figure 2. (a) Sentinel-1 imagery track numbers and acquisition details; connection graphs: (b) time-position plot for SBAS; (c) time-baseline plot for SBAS. 


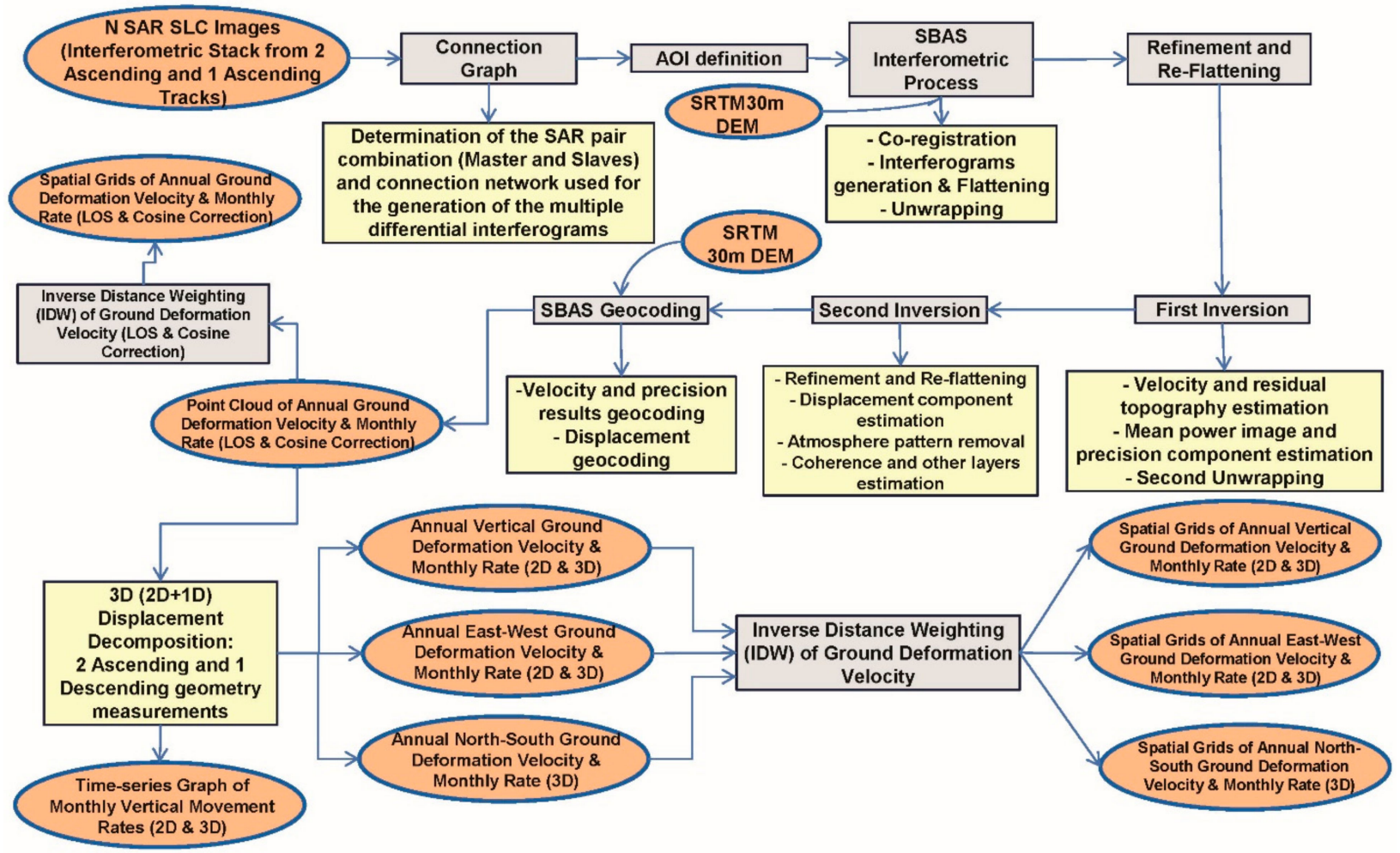

Figure 3. Workflow of SBAS interferometric processing followed by 2D and 3D decompositions, cosine correction and geostatistical interpolations.

According to Fuhrmannet al. [16], Chang et al. [39] and Hanssen [40] for 3D decomposition with three-track InSAR LOS measurements, the following Equation (2) can be written:

$$
\left(\begin{array}{l}
d_{L O S}^{1} \\
d_{L O S}^{2} \\
d_{L O S}^{3}
\end{array}\right)=\left(\begin{array}{ccc}
\cos \theta_{1} & \sin \theta_{1} \sin \alpha_{1} & -\sin \theta_{1} \sin \alpha_{1} \\
\cos \theta_{2} & \sin \theta_{2} \sin \alpha_{2} & -\sin \theta_{2} \sin \alpha_{2} \\
\cos \theta_{3} & \sin \theta_{3} \sin \alpha_{3} & -\sin \theta_{3} \sin \alpha_{3}
\end{array}\right)\left(\begin{array}{c}
d_{\text {vert }(\text { Up-Down })} \\
d_{\text {hor (North-South) }} \\
d_{\text {hor (East-West) }}
\end{array}\right)
$$

In the case of the cosine correction technique, it is simply assumed that all motions are vertical and horizontal velocities are neglected. Therefore, the vertical velocity can be obtained through dividing the LOS displacement rates by the cosine of the radar incidence angle as follows below in Equation (3) [17,41]:

$$
d_{\text {vert }(U p-\text { Down })}=\left(d_{L O S} / \cos \theta\right)
$$

Furthermore, inverse distance weighting (IDW) interpolations were used to develop the continuous grid models of ground deformations for simplified interpretation of movements and geospatial analysis. The contextual information of seismic faults and wells were also used to understand how SBAS- detected ground deformations were related to natural and man-made factors.

\section{Results}

The annual average vertical deformation velocity in the LOS was observed to be in the range of $-56.86-25.49 \mathrm{~mm} / \mathrm{y}$ over the Tengiz field during 2018-2020 (Figure 4a) for Ascending track 1 (Path: 57, Frame: 148, Absolute Orbit: 30579), $-60.3-29.26 \mathrm{~mm} / \mathrm{y}$ (Figure 4b) for Ascending track 2 (Path: 159, Frame: 149, Absolute Orbit: 35931) and -58.93-22.65 mm/y (Figure 4c) for Descending Track (Path: 35, Frame: 441; Absolute Orbit: 30557). The spatial distribution histogram of measured LOS velocities is presented in Figure $4 \mathrm{~d}$. It is possible to clearly observe the prevailing subsidence processes at the Tengiz 
field based on the number of pixels with negative values. The presence of seismic faults that are well aligned with the spatial distribution of subsidence patterns allow one to assume that besides the primary man-made oil extraction factor, the ground deformation processes are also controlled by natural tectonic factors. It is also possible to assume that significantly subsiding areas of Tengiz field are not spatially related to the concentration of wells but rather triggered by the production and injection activities related to natural subsurface tectonic features. Based on the studies by Grebby et al. [1] conducted for the period of 2016-2017 using Sentinel-1 images and ENVISAT images for the period of 2004-2009, it is possible to conclude that the Tengiz oilfield continues to subside.

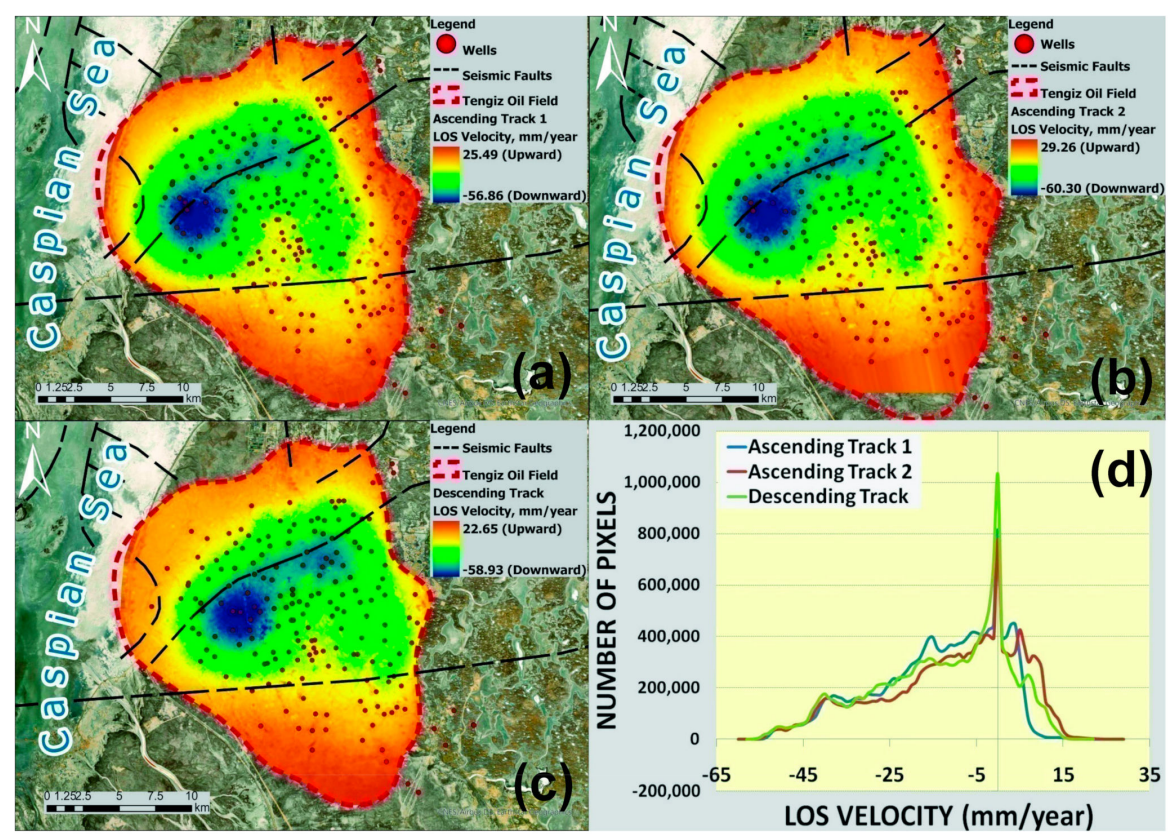

Figure 4. Stacking-derived LOS deformation velocity of the Tengiz oilfield: (a) ascending track 1; (b) ascending track 2; (c) descending; (d) histogram of LOS velocity distribution.

It is necessary to emphasize that the significant variations in the spatial distribution of ground deformation values in LOS measurements might be obviously a challenge for oil and gas industry in the terms of a reliable approach on the ground for operational planning (Figure 4d). Besides, it is necessary to emphasize that the geo-position of the actual vertical displacement locations might also be confusing for oil and gas operators in case of the LOS measurements.

The 3D and 2D decompositions of LOS measurements 2018-2020 to vertical displacement allowed to determine that annual average vertical deformation velocity over the Tengiz oilfield was in the range of $-70.04-22.44 \mathrm{~mm} /$ year and $-73.29-23.70 \mathrm{~mm} /$ year, respectively (Figure 5a,b). The range of vertical subsidence velocities was observed to be slightly higher than in case of LOS measurements. Based on the Pearson Correlation Coefficient $>90$ and $t$-test $p$-value $>0.05$ in Figure $5 c, d$, it is possible to conclude that both 3D and 2D decompositions produced identical vertical deformation velocities with an RMSE of $1.86 \mathrm{~mm}$. Even though many research activities applied the LOS measurements for the operational purposes of oil and gas fields, as mentioned before, it was possible to observe differences in LOS displacements compared to 3D and 2D decomposition results (Figure 5d). The RMSE between vertical displacements of 3D decompositions and LOS measurements derived from Ascending 1, Ascending 2 and Descending tracks were $13 \mathrm{~mm}, 12 \mathrm{~mm}$ and $10 \mathrm{~mm}$, respectively. The $t$-test $p$-value was lower than 0.05 what implies that there is a significant difference between $L O S$ measurements and 3D- and 2D-decomposed vertical deformation velocities. As it is possible to derive from Figure $5 \mathrm{~d}$, no horizontal geopositional displacements were observed along the profile. Along the 
profile in Figure 5a,b, it was possible to observe differences between 3D decomposition vertical deformation and $L O S$ velocities in the range of 7-21 $\mathrm{mm}$ (Figure $5 \mathrm{~d}$ ).

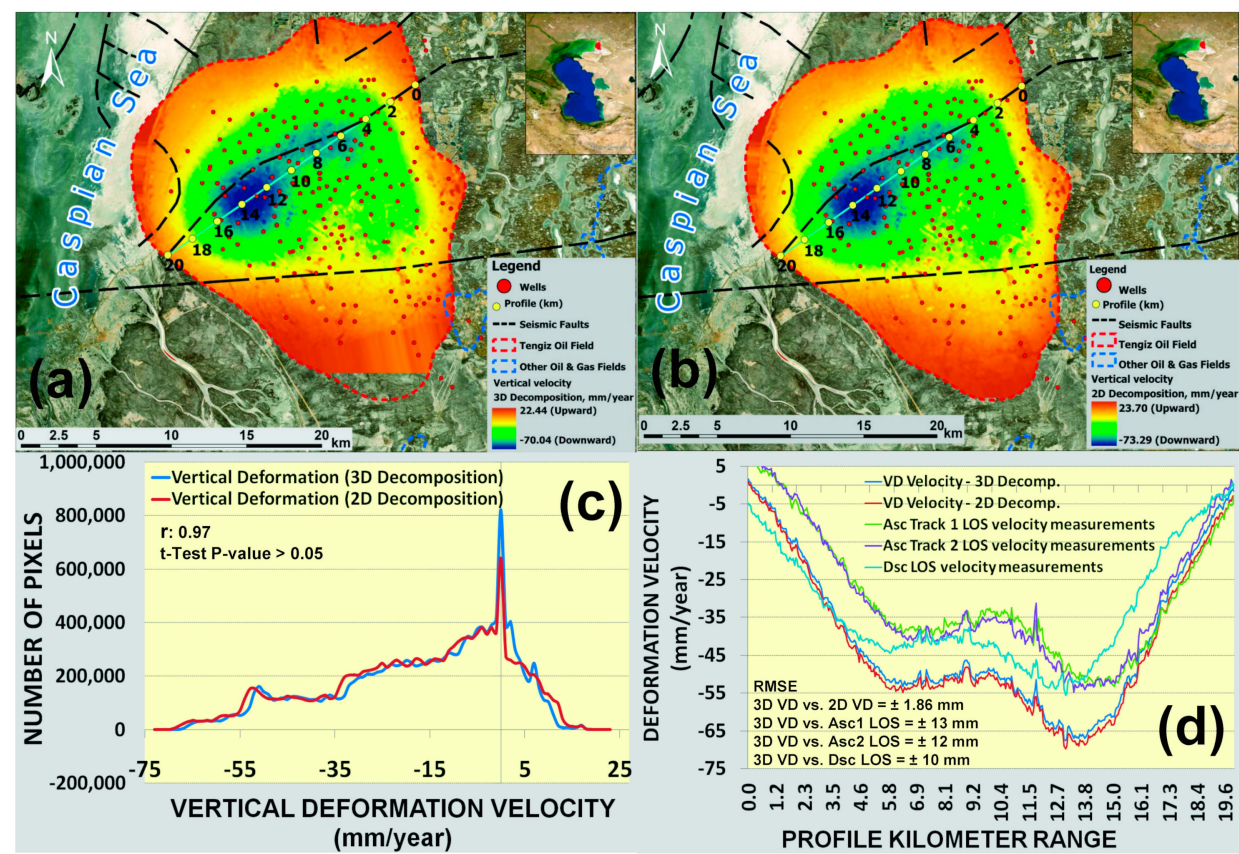

Figure 5. Vertical deformation velocity derived: (a) from 3D decomposition of 2 ascending and 1 descending LOS measurements; (b) from 2D decomposition of 1 ascending and 1 descending LOS measurements; (c) histogram of vertical deformation velocities derived from 3D and 2D decompositions; (d) profiles of vertical deformation velocities derived from 3D and 2D decompositions and LOS measurements.

The vertical velocity obtained through the division of the LOS displacement rates by the cosine of the radar incidence angle is presented in Figure 6a-c. The histogram of vertical velocity distribution derived from cosine correction is presented in Figure 6d. Like the previously mentioned histogram of LOS measurements, in this case it was also possible to observe significant variations in the spatial distribution of ground deformation values (Figure 6d). These variations might also create a challenge and uncertainties for the oil and gas operators even though the cosine correction was applied to derive vertical deformation velocity. However, the RMSE between vertical deformation velocities derived from cosine correction and from $3 \mathrm{D}$ decomposition reduced twice with the variation in the range of 6-8 millimeter. Along the profiles in Figure $6 \mathrm{a}-\mathrm{c}$ it was possible to observe differences between 3D decomposition vertical deformation and cosine-corrected velocities in the range of $0-17 \mathrm{~mm}$ (Figure 6e). It is possible to conclude that the cosine correction of LOS measurements to vertical deformation velocity obviously improved the overall reliability of ground movement measurements. However, it is still possible to observe variations along the profile which may also create a different kind of uncertainties for the operators of oil and gas fields.

The hotspot of significant subsidence is located at the intersection of profile lines in Figure 7a,b. The location of maximum subsidence velocity was also observed at the intersection of profiles indicated in Figure $7 \mathrm{a}$. As it is possible to see in Figure $7 \mathrm{~b}$, the maximum annual vertical deformation velocity of maximum subsidence along profiles reaches about $70 \mathrm{~mm}$. Location and time series of cumulative ground displacement rates of the maximum subsiding position are presented in Figure $7 c, d$, respectively, for LOS measurements and their 2D and 3D decompositions to vertical movements. The ground deformation rate at the maximum subsiding location reaches about $200 \mathrm{~mm}$ of vertical ground movement derived from 3D decomposition of LOS measurements over the period of 2018-2020 (Figure 7c,d). The differences of vertical deformation rates derived from 
3D decomposition and cosine corrections at the maximum subsiding site vary in the range of 0-50 mm (Figure 7d). RMSE between vertical deformation rates from 3D and 2D decompositions and cosine correction was observed to be in the range of 30-40 mm (Figure 7d).

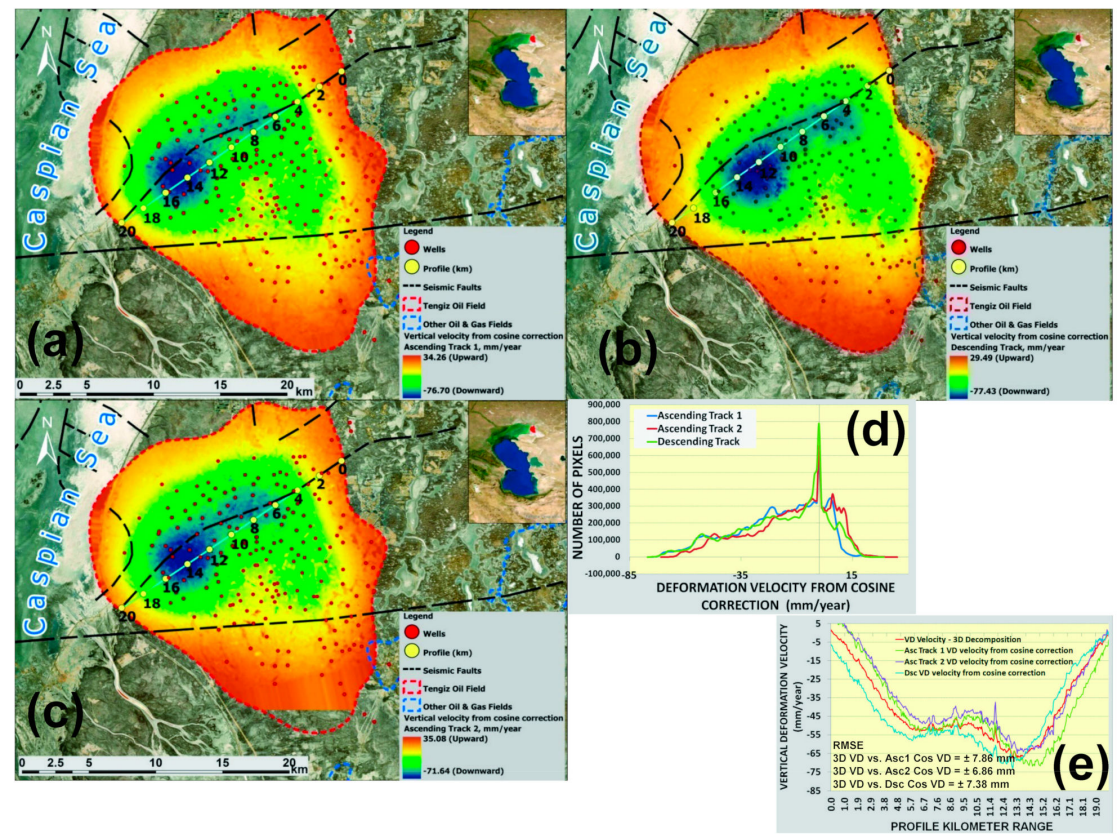

Figure 6. Vertical deformation velocity derived from cosine correction: (a) Ascending track 1; (b) Descending Track; (c) Ascending Track 2; (d) histogram of vertical velocity distribution derived from cosine correction; (e) comparison of vertical velocity profiles derived from 3D decompositions and cosine corrections.
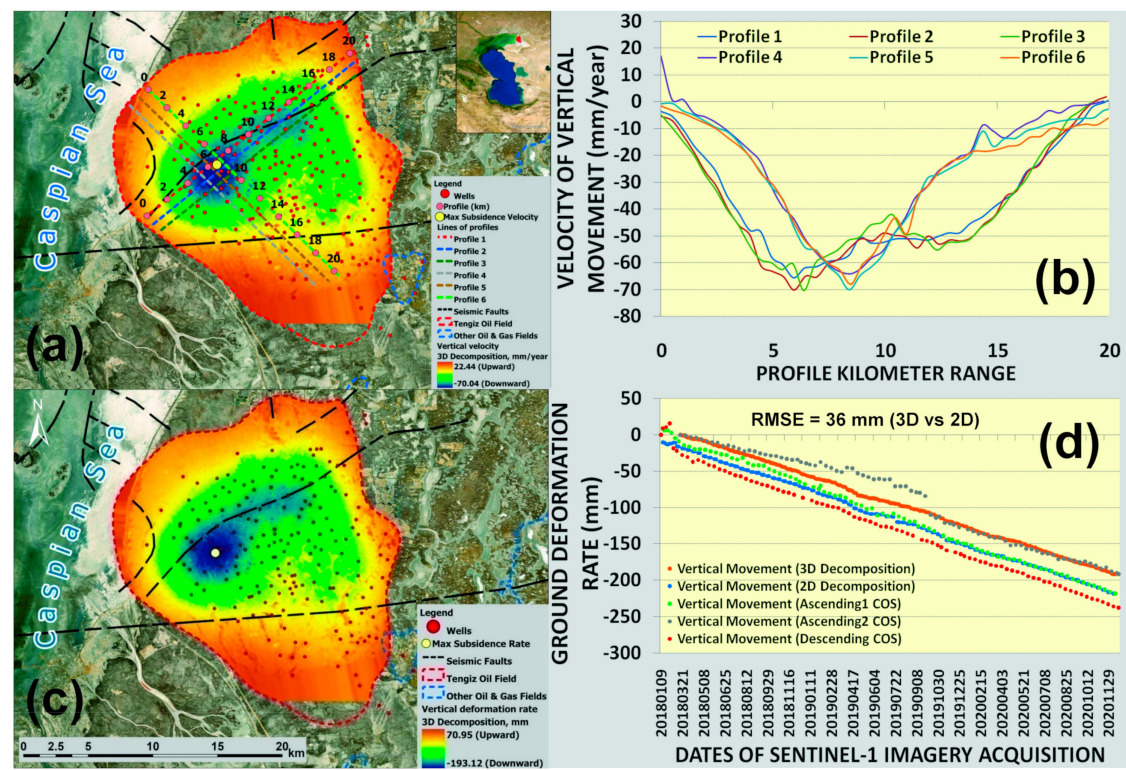

Figure 7. (a) Location of maximum subsidence in the area of vertical deformation velocity derived from 3D decomposition; (b) Profiles of vertical movement velocity; (c) Maximum subsiding location with the background of vertical deformation rate derived from 3D decomposition; (d) Vertical deformation rates derived from 3D and 2D decompositions and cosine corrections for the location of maximum subsidence. 
The 3D and 2D decomposition of LOS measurements 2018-2020 to horizontal east-west displacement allowed to determine that annual average horizontal deformation velocity over the Tengiz oilfield was in the range of $-25.48-21.33 \mathrm{~mm} /$ year and $-23.17-22.82 \mathrm{~mm} /$ year, respectively (Figure 8a,b). Although the annual average horizontal deformation velocity was not significant, it was interesting to find both eastward and westward horizontal movements. Based on the Pearson Correlation Coefficient $>80$ and a $t$-test $p$-value $>0.05$ in Figure 8c,d, it is possible to conclude that both 3D and 2D decompositions produced identical horizontal deformation velocities with an RMSE of $1.62 \mathrm{~mm}$. This allows to state that 2D decomposition of LOS measurements will be sufficient for the future deformation analysis by oil and gas operators of the Tengiz oilfield.

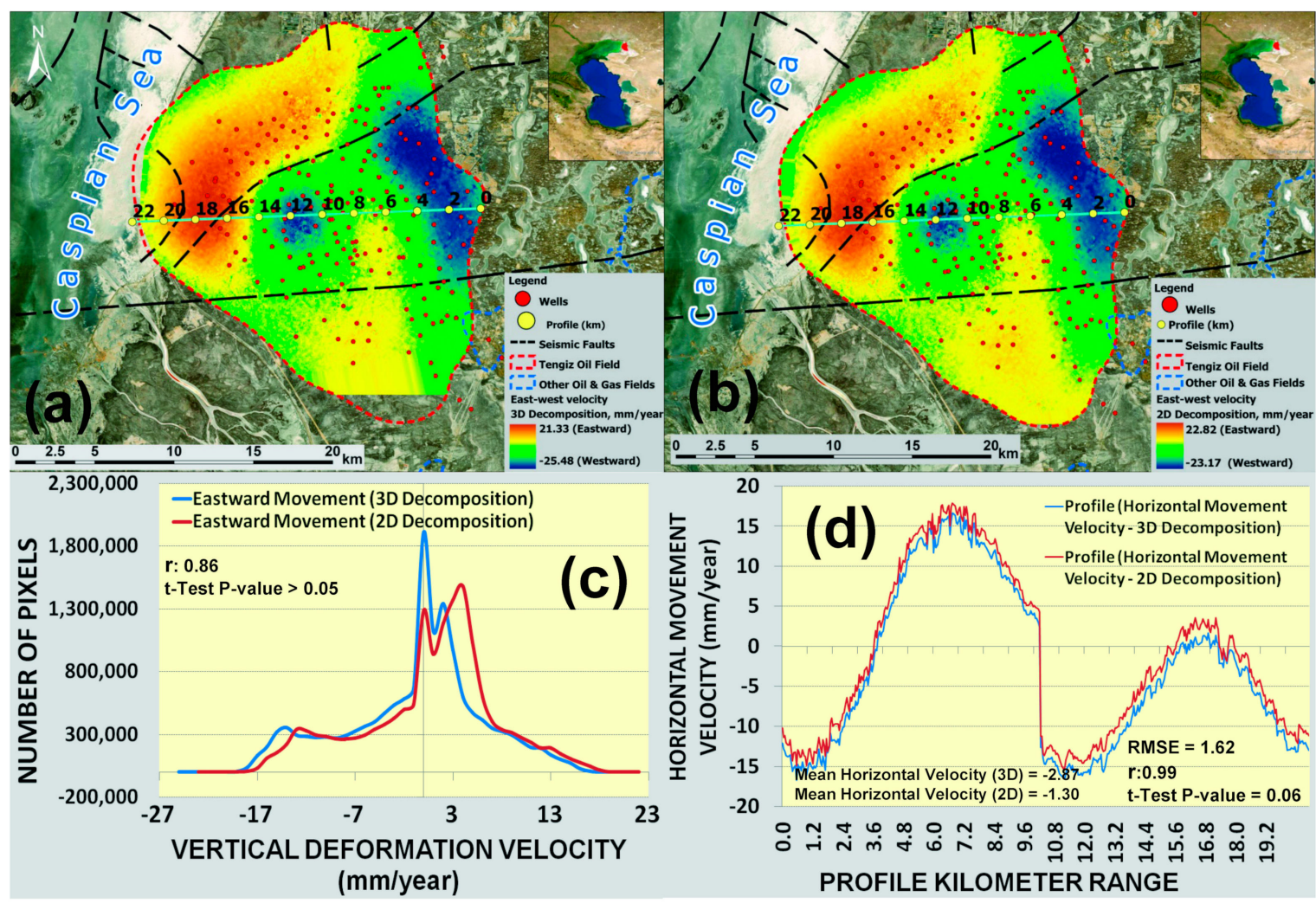

Figure 8. East-west movement velocity derived from: (a) 3D decomposition of 2 ascending and 1 descending LOS measurements; (b) 2D decomposition of 1 ascending and 1 descending LOS measurements; (c) histogram of east-west movement velocities derived from 3D and 2D decompositions; (d) profiles of east-west movement velocities derived from 3D and 2D decompositions.

The 3D decomposition of LOS measurements 2018-2020 to horizontal north-south displacement allowed to determine an annual velocity over the Tengiz oilfield in the range of $-5.54-8.12 \mathrm{~mm} /$ year (Figure 9a). Even though the north-south movement was not significant (Figure 9b), the interesting pattern of the Tengiz oilfield northern area moving southward and southern area moving northward towards seismic fault was observed. This, in return, allowed to assume that this area is under the impact of natural, i.e., not man-made, tectonic processes as it was also determined by Anissimov et al. [26].

This fact may increase the negative impacts on the Tengiz oilfield through the acceleration of the subsidence processes caused by the man-made oil extraction processes. The spatial relationships between the seismic faults and horizontal and vertical movements were well reflected in the 3D representation of the ground deformation velocities (Figure 10a-d). 


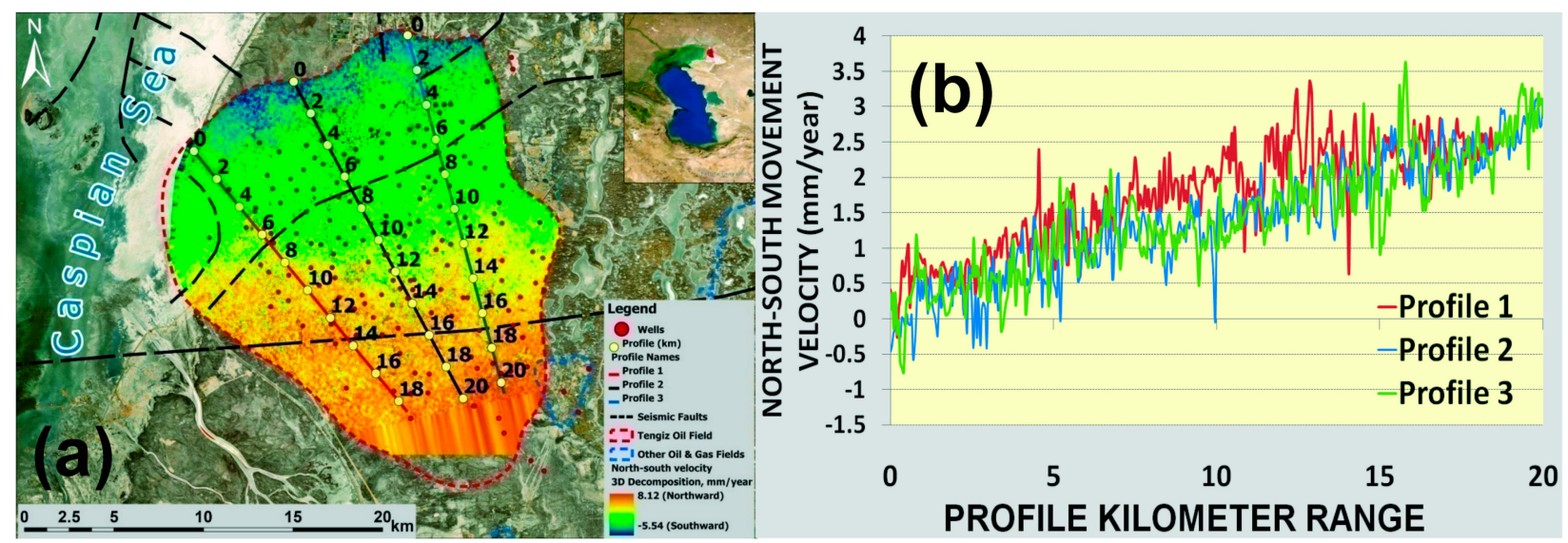

Figure 9. (a) North-south movement velocity derived from 3D decomposition of 2 ascending and 1 descending LOS measurements; (b) North-south movement velocity along profiles.

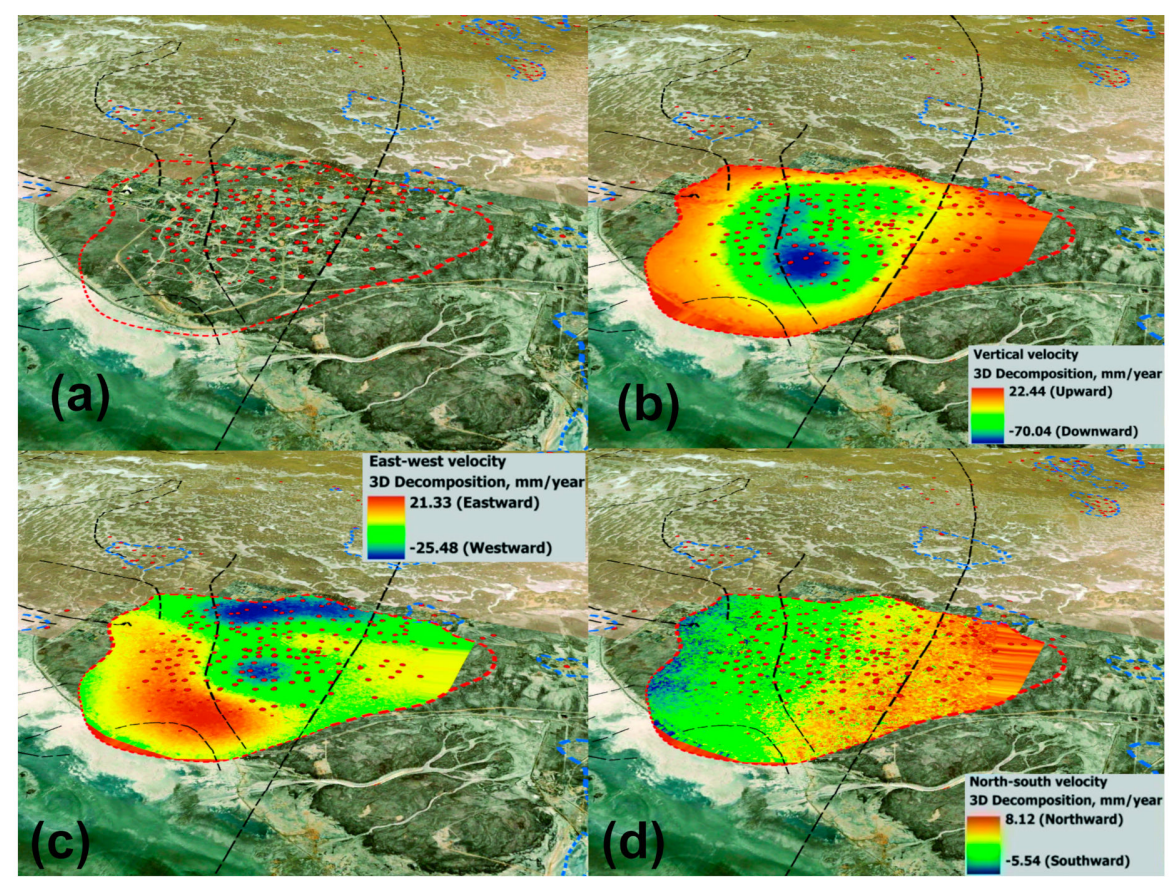

Figure 10. Oblique aerial view of: (a) Tengiz oilfield; (b) vertical deformation velocity derived from 3D decomposition; (c) east-west movement velocity derived from 3D decomposition; (d) north-west movement velocity from derived from $3 \mathrm{D}$ decomposition.

Unfortunately, because of the absence of historical cumulative high-precision GPS measurements, it was not possible to validate the SBAS measurements, the results of 2D and $3 \mathrm{D}$ decompositions and cosine corrections. The only possible qualitative judgment was conducted based on the studies by Grebby et al. [1] which also revealed a continuous subsidence at the Tengiz oilfield.

\section{Discussion}

Based on the results of the present research and the previous studies by Grebby et al. [1], Orynbassarova [2], Comola et al. [8] and Del Conte et al. [9] it was possible to conclude that the subsidence processes in the Tengiz field continue with increasing velocity. 3D and 2D decompositions of LOS measurements concerning vertical deformation revealed twice lower differences in comparison to cosine correction than with LOS measurements. According to Del Conte et al. [9], Rocca et al. [42], and Ferretti et al. [43] the availability of hundreds of measurement of points per $\mathrm{km}^{2}$ with millimeter-level precision is required 
as one of the inputs for reservoir monitoring, characterization, geomechanical analysis, induced seismicity, assessment of the surface effects of pressure variations and fault reactivation due to either fluid extraction or injection. This allows to assume that even though at the large scale of the Tengiz oil field the differences between ground deformation velocities of 3D and 2D decompositions, cosine corrections and LOS measurement are not so significant. Hence it is recommended to use the most accurate measurements of ground deformations. The role of $3 \mathrm{D}$ and $2 \mathrm{D}$ decompositions to vertical velocities becomes even more indicative in this case, if sufficient number of SAR data is available from ascending and descending tracks. According to Tamburini et al. [44], the depth of the reservoir should also be considered in order to assess the usefulness of InSAR technology to measure surface effects of the reservoir exploitation and also to use the surface deformation data in conjunction with other surface and subsurface measurements.

Even though the vertical deformation confirmed typical patterns of subsidence caused by oil extraction, detected east-west and north-south movements at the Tengiz oilfield clearly indicated that the study area crossed by seismic faults is affected by natural tectonic processes. It is necessary to emphasize that the spatial patterns of east-west and northsouth ground movements were observed to both sides of the seismic faults. A seismic fault was also observed crossing the detected hotspot of subsidence. This means that the natural tectonic processes at the Tengiz oilfield should also be considered as one of the significant risk factors which might have significant consequences like induced seismicity and infrastructure failure as a result of ongoing oil field exploitation.

The present research results, however, also exhibit shortcomings. It was not possible to validate the vertical, east-west and north-south ground deformation velocities because of the absence of historical geodetic measurements. Repeating this study with data from COSMO-SkyMed radar images which are another source with sufficient coverage for the Tengiz oilfield would serve well to cross-validate the results of the present research. As mentioned before, the only possible qualitative judgment was conducted on the basis of the studies by Grebby et al. [1] which also revealed continuous subsidence in the Tengiz oilfield. Another shortcoming is that for the specific operational maintenance of terminals and wells, it is recommended to run the Persistent Scatterer Interferometric Synthetic Aperture Radar (PS-InSAR) remote sensing technique within the required infrastructural area of interest. PS-InSAR is more effective and accurate to identify persistently reflecting ground features and their motion rates with millimeter precision [45-48]. PS-InSAR is able to compute deformation rates at millimeter level, requiring a minimum of 20 SAR images in order to achieve statistically reliable persistent scatterers, to estimate a more reliable phase and also to addresses the problems of decorrelation [49]. Running of PS-InSAR for the entire area of the Tengiz oilfield was not successful in the present research, in particular because of the terrain surface's low-backscattering characteristics; therefore it was not selected as one of the computational techniques. PS-InSAR technique would also perform well with the installation of the corner reflectors for the prioritized sites of interest.

The outcomes of the present research suggest to the operators of oil and gas fields to initially evaluate required standards and precision of measurements depending on the operational needs. In particular oil and gas operators should be aware that even though LOS measurements present the overall ground movement patterns, they do not reflect true vertical movement values at the local scale. Therefore, planning of actual risk mitigation and remediation measures on the ground might be misleading unless LOS measurements are decomposed to vertical deformation velocities and rates. If in-situ time-series data of geodetic measurements are available, according to Zhou et al. [50], it is recommended to calibrate the results of InSAR measurements for the validation and enhancement of the precision.

For emergency cases with short operational timeframes allowing only vertical and east-west deformations or insufficient number of collected images from different tracks, based on the comparative assessments between $2 \mathrm{D}$ and $3 \mathrm{D}$, it is sufficient to apply $2 \mathrm{D}$ decomposition using LOS measurements from one ascending and one descending, two 
ascending or two descending tracks. In the case of emergency, unless the operators are interested in horizontal movements, it is also possible to apply cosine correction from LOS measurements to achieve vertical deformations, certainly if the defined organizational precision standards allow this.

\section{Conclusions}

The present research investigated the surface deformations induced by man-made production and natural processes in the Tengiz oilfield using SBAS technique and 3D and 2D decompositions of LOS measurements to vertical and horizontal deformations. Our conclusions and recommendations are as follows:

(1) 3D decomposition of LOS measurements concerning vertical movements showed that the Tengiz oilfield continued to subside during 2018-2020 with a maximum annual vertical deformation velocity around $70 \mathrm{~mm}$. Following LOS measurements, the maximum annual subsiding velocity was observed to be $60 \mathrm{~mm}$. Cosine corrections of LOS measurements to vertical movement revealed a maximum annual vertical deformation velocity of $77 \mathrm{~mm}$.

(2) Overall RMSE between 3D decomposed vertical deformation and LOS measurements was observed to be in the range of $10-13 \mathrm{~mm}$. The differences on the local level were variable in the range of 7-21 $\mathrm{mm}$.

(3) Overall RMSE between 3D decomposed and cosine-corrected vertical deformations was observed to be in the range of $6-8 \mathrm{~mm}$. Compared to LOS measurements, the cosine-correction improved the results of vertical deformation twice relative to 3D and $2 \mathrm{D}$ decomposition. The differences on the local level were variable in the range of $0-17 \mathrm{~mm}$.

(4) The ground deformation rate at the location of maximum subsidence reached around $200 \mathrm{~mm}$ of vertical ground movement derived from 3D decomposition of LOS measurements over the period of 2018-2020. The differences of vertical deformation rates derived from 3D decomposition and cosine corrections at the site of the maximum subsidence varied in the range of $0-50 \mathrm{~mm}$. RMSE between vertical deformation rates from $3 \mathrm{D}$ and $2 \mathrm{D}$ decompositions and cosine correction was observed to be in the range of 30-40 mm. Besides the ground deformation velocity, it is highly important to consider the total displacement reflected in the deformation rate of individual sites of interest.

(5) The vertical deformation confirmed typical patterns of subsidence caused by oil extraction. Detected east-west and north-south movements at the Tengiz oilfield clearly indicated that the study area crossed by seismic faults is affected by natural tectonic processes. It has to be emphasized that the spatial patterns of east-west and north-south ground movements were observed on both sides of seismic fault crossing the detected hotspot of subsidence. It is possible to conclude that the natural tectonic process at the Tengiz field is one of the significant risk factors which might have significant consequences like induced seismicity and infrastructure failure as a result of ongoing man-made oil field exploitation.

It is critical for operators of oil and gas fields and also other types of oil and gas infrastructure to realize the actual differences of ground deformation measurements derived from 3D and 2D decompositions, cosine correction and LOS measurements. This will allow to initially evaluate the required standard and precision of measurements depending on operational needs, timeframes and availability of imagery. Since it was not possible to validate the results of the present research, it is planned to use higher resolution SAR sensors to cross-validate the achieved results. 
Author Contributions: Scientific research and writing of original draft: E.B.; Review and editing: M.B. and M.K.; Resources: Y.Z. All authors have read and agreed to the published version of the manuscript.

Funding: This research was funded by the Nazarbayev University through the Faculty-development Competitive Research Grant (FDCRGP)—Funder Project Reference: 080420FD1917.

Acknowledgments: The authors would like to thank Nazarbayev University. This research was funded by the Nazarbayev University through the Faculty-development Competitive Research Grant (FDCRGP)—Funder Project Reference: 080420FD1917.

Conflicts of Interest: The authors declare no conflict of interest.

\section{References}

1. Grebby, S.; Orynbassarova, E.; Sowter, A.; Gee, D.; Athab, A. Delineating ground deformation over the Tengizoilfield, Kazakhstan, using the Intermittent SBAS(ISBAS)DInSARalgorithm. Int. J. Appl. EarthObs. Geoinf. 2019, 81, 37-46. [CrossRef]

2. Orynbassarova, E. Improvement of the method of integrated preparation and use of space images in tasks of assessment of sedimentation of industrial surface in the conditions of operation of Tengiz oil and gas field. Ph.D. Thesis, Satbayev University, Almaty, Kazakhstan, 2019.

3. Bayramov, E.; Buchroithner, M.; Kada, M. Quantitative Assessment of Ground Deformations for the Risk Management of Petroleum and Gas Pipelines Using Radar Interferometry. Geomat. Nat. Hazards Risk 2020, 11, 2540-2568. [CrossRef]

4. Bayramov, E.; Buchroithner, M.; Kada, M. Radar Remote Sensing to Supplement Pipeline Surveillance Programs through Measurements of Surface Deformations and Identification of Geohazard Risks. Remote. Sens. 2020, 12, 3934. [CrossRef]

5. Bayramov, E.; Buchroithner, M.; Kada, M.; Bayramov, R. Quantitative assessment of ground deformation risks, controlling factors and movement trends for onshore petroleum and gas industry using satellite Radar remote sensing and spatial statistics. In Georisk: Assessment and Management of Risk for Engineered Systems and Geohazards; Taylor \& Francis: London, UK, 2020. [CrossRef]

6. Mirzaii, Z.; Hasanlou, M.; Samieie-Esfahany, S.; Rojhani, M.; Ajourlou, P. Land Subsidence Monitoring in Azar Oil Field Based on Time Series Analysis. Proceedings 2019, 18, 2. [CrossRef]

7. Shi, J.; Yang, H.; Peng, J.; Wu, L.; Xu, B.; Liu, Y.; Zhao, B. InSAR Monitoring and analysis of ground deformation due to fluid or gas injection in Fengcheng oil field, Xinjiang, China. J. Indian Soc. Remote Sens. 2019, 47, 455-466. [CrossRef]

8. Comola, F.; Janna, C.; Lovison, A.; Minini, M.; Tamburini, A.; Teatini, P. Efficient global optimization of reservoir geomechanical parameters based on synthetic aperture radar-derived ground displacements. Geophysics 2016, 81, M23-M33. [CrossRef]

9. Del Conte, S.; Tamburini, A.; Cespa, S.; Rucci, A.; Ferretti, A. Advanced InSAR Technology for Reservoir Monitoring and Geomechanical Model Calibration. In Proceedings of the SPE Kuwait Oil and Gas Show and Conference, Kuwait City, Kuwait, 8-10 October 2013. [CrossRef]

10. Katrenov, Z.; Tlepbergenov, N.; Flodin, E.; Buchmann, T.; Connolly, P. Mechanical Earth Modeling of the Tengiz Field. In Proceedings of the Conference Proceedings of the 2nd EAGE International Conference KazGeo, Almaty, Kazakhstan, 29-31 October 2012.

11. Zhantaev, J.; Fremd, A.; Ivanchukova, A.; Kaldybayev, A.; Nurakynov, S.; Kantemirov, Y.; Nikiforov, S. Satellite radar monitoring of land surface subsidence over Tengiz oil and gas field. Geomat. Mag. 2012, 1, 61-71. (In Russian)

12. Zhantayev, Z.; Kurmanov, B.; Bibosynov, A.; Fremd, A.; Ivanchukova, A. Persistent Scatterers Interferometry Technique for Urban Subsidence Monitoring in Kazakhstan Republic. ProcediaTechnol. 2014, 16, 583-587. [CrossRef]

13. Junisbekova, V.; Filatov, A.; Kuznetsova, I.; Yelisseyeva, A. SAR Interferometry Technique For Ground Deformation Assessment On Karazhanbas Oil field. Procedia Comput. Sci. 2016, 100, 1163-1167.

14. Togaibekov, A.Z. Monitoring of Oil-Production-Induced Subsidence and Uplift. Master's Thesis, Massachusetts Institute of Technology, Cambridge, MA, USA, 2020.

15. Mozer, D.V.; Tuyakbai, A.S.; Toleubekova, Z.Z. State of the undermined Karaganda Coal Basin area by satellite monitoring data. J. Min. Sci. 2017, 53, 389-395. [CrossRef]

16. Fuhrmann, T.; Garthwaite, M.C. Resolving Three-Dimensional Surface Motion with InSAR: Constraints from Multi-Geometry Data Fusion. Remote Sens. 2019, 11, 241. [CrossRef]

17. Yang, Y.-J.; Hwang, C.; Hung, W.-C.; Fuhrmann, T.; Chen, Y.-A.; Wei, S.-H. Surface Deformation from Sentinel-1A InSAR: Relation to Seasonal Groundwater Extraction and Rainfall in Central Taiwan. Remote Sens. 2019, 11, 2817. [CrossRef]

18. Fernandez, J.; Prieto, J.F.; Escayo, J.; Camacho, A.; Luzon, F.; Tiampo, K.; Palano, M.; Abajo, T.; Perez, E.; Valasco, J.; et al. Modeling the two- and three- dimensional displacement field in Lorca, Spain, subsidence and the global implications. Sci. Rep. 2018, 8, 14782. [CrossRef]

19. Staniewicz, S.; Chen, J.; Lee, H.; Olson, J.; Savvaidis, A.; Reedy, R.; Breton, C.; Rathje, E.; Hennings, P. InSAR reveals complex surface deformation patterns over an $80,000 \mathrm{~km} 2$ oil-producing region in the Permian Basin. Geophys. Res. Lett. 2020, 47, e2020GL090151. [CrossRef]

20. Even, M.; Westerhaus, M.; Simon, V. Complex Surface Displacements above the Storage Cavern Field at Epe, NW-Germany, Observed by Multi-Temporal SAR-Interferometry. Remote Sens. 2020, 12, 3348. [CrossRef] 
21. Liu, X.; Hu, J.; Sun, Q.; Li, Z.; Zhu, J. Deriving 3-DTime-Series Ground Deformations Induced by Underground Fluid Flows with InSAR: Case Study of Sebei Gas Fields, China. Remote Sens. 2017, 9, 1129. [CrossRef]

22. Klemm, H.; Quseimi, I.; Novali, F.; Ferretti, A.; Tamburini, A. Monitoring horizontal and vertical surface deformation over a hydrocarbon reservoir by PSInSAR. First Break 2010, 28, 5. [CrossRef]

23. Klein, I.; Gessner, U.; Kuenzer, C. Regional land cover mapping and changed detection in Central Asia using MODIS time-series. Appl. Geogr. 2012, 35, 219-234. [CrossRef]

24. Bealessio, B.A.; Blánquez Alonso, N.A.; Mendes, N.J.; Sande, A.V.; Hascakir, B. A review of enhanced oil recovery(EOR) methods applied in Kazakhstan. Petroleum 2020, 7, 1-9. [CrossRef]

25. Sokolova, I.N.; Mikhailova, N.N.; Velikanov, A.E.; Poleshko, N.N. Induced seismicity on the territory of Kazakhstan. In Book of Abstracts CTBT: Scienceand Technology Conference; CTBTO: Vienna, Austria, 2017.

26. Anissimov, L.; Postnova, E.; Merkulov, O. Tengiz oilfield: Geological model based on hydrodynamic data. Petroleum Geosci. 2020, 6, 59-65. [CrossRef]

27. Imamoglu, M.; Kahraman, F.; Çakir, Z.; Sanli, F.B. Ground Deformation Analysis of Bolvadin (W.Turkey) by Means of MultiTemporal InSAR Techniques and Sentinel-1 Data. Remote Sens. 2019, 11, 1069. [CrossRef]

28. Yang, C.; Zhang, D.; Zhao, C.; Han, B.; Sun, R.; Du, J.; Chen, L. Ground Deformation Revealed by Sentinel-1 MSBAS-InSAR Time-Series over Karamay Oil field, China. Remote Sens. 2019, 11, 2027. [CrossRef]

29. Loesch, E.; Sagan, V. SBAS Analysis of Induced Ground Surface Deformation from Waste water Injection in East Central Oklahoma, USA. Remote Sens. 2018, 10, 283. [CrossRef]

30. Farr, T.; Rosen, P.; Caro, E.; Crippen, R.; Duren, R.; Hensley, S.; Alsdorf, D. The shuttle radar topography mission. Rev. Geophys. 2007, 45. [CrossRef]

31. Vassileva, M.; Tonolo, F.G.; Riccardi, P.; Lecci, D.; Boccardo, P.; Chiesa, G. Satellite SAR interferometric techniques in support to emergency mapping. Eur. J. Remote Sens. 2017, 50, 464-477. [CrossRef]

32. Aslan, G.; Cakir, Z.; Lasserre, C.; Renard, F. Investigating Subsidence in the Bursa Plain, Turkey, Using Ascending and Descending Sentinel-1 Satellite Data. Remote Sens. 2019, 11, 85. [CrossRef]

33. Fialko, Y. Interseismic strain accumulation and the earthquake potential on the southern San Andreas Fault system. Nature 2006, 441, 968. [CrossRef]

34. Motagh, M.; Shamshiri, R.; Haghighi, M.H.; Wetzel, H.U.; Akbari, B.; Nahavandchi, H.; Roessner, S.; Arabi, S. Quantifying ground water exploitation induced subsidence in the Rafsanjan plain, Southeastern Iran, using InSAR time-series and in situ measurements. Eng. Geol. 2017, 218, 134-151. [CrossRef]

35. Alatza, S.; Papoutsis, I.; Paradissis, D.; Kontoes, C.; Papadopoulos, G.A. Multi-Temporal InSAR Analysis for Monitoring Ground Deformation in Amorgos Island, Greece. Sensors 2020, 20, 338. [CrossRef] [PubMed]

36. Ho Tong Minh, D.; NGO, Y.; Lê, T.T.; Le, T.C.; Bui, H.S.; Vuong, Q.V.; LeToan, T. Quantifying Horizontal and Vertical Movements in Ho Chi Minh City by Sentinel-1RadarInterferometry. Preprints 2020. [CrossRef]

37. Pawluszek-Filipiak, K.; Borkowski, A. Integration of DInSAR and SBAS Techniques to Determine Mining-Related Deformations Using Sentinel-1 Data:The Case Study of Rydułtowy Mine in Poland. RemoteSens. 2020, 12, 242.

38. Aslan, G. Monitoring of Surface Deformation in Northwest Turkey from High-Resolution Insar: Focus on Tectonic Aseismic Slip and Subsidence. Tectonics. Ph.D. Thesis, ISTANBUL Tekniküniversitesi, Istanbul, Turkey, 2019. Available online: https: // tel.archives-ouvertes.fr/tel-02271771/document (accessed on 1 July 2021).

39. Chang, Z.; Yu, W.; Wang, W.; Zhang, J.; Liu, X.; Zhu, J. An approach for accurately retrieving the vertical deformation component from two track InSAR measurements. Int. J. Remote Sens. 2017, 38, 1702-1719. [CrossRef]

40. Hanssen, R.F. Radar Interferometry: Data Interpretation and Error Analysis; Kluwer Academic Publishers: Dordrecht, The Netherlands, 2001.

41. Gee, D.; Sowter, A.; Novellino, A.; Marsh, S.; Gluyas, J. Monitoring land motion due to natural gas extraction: Validation of the Intermittent SBAS(ISBAS) DInSAR algorithm over gas fields of North Holland, TheNetherlands. Mar. Pet. Geol. 2016, 77, 1338-1354. [CrossRef]

42. Rocca, F.; Rucci, A.; Ferretti, A.; Bohane, A. Advanced InSAR interferometry for reservoir monitoring. First Break 2013, 31 , 77-85. [CrossRef]

43. Ferretti, A.; Tamburini, A.; Novali, F.; Fumagalli, A.; Falorni, G.; Rucci, A. Impact of high resolution radar imagery on reservoir monitoring. Energy Procedia 2011, 4, 3465-3471. [CrossRef]

44. Tamburini, A.; Bianchi, M.; Giannico, C.; Novali, F. Retrieving Surface Deformation by PSInsar ${ }^{\mathrm{TM}}$ Technology: A Powerful Tool in Reservoir Monitoring. Int. J. Greenh. Gas.Control. 2010, 4, 928-937. [CrossRef]

45. Ferretti, A.; Prati, C. Rocca, F. Nonlinear Subsidence Rate Estimation Using Permanent Scatterers in Differential SAR Interferometry. IEEE Trans.Geosci. Remote. Sens. 2000, 38, 2202-2212. [CrossRef]

46. Ferretti, A.; Prati, C.; Rocca, F.; Casagli, N.; Farina, P.; Young, B. Permanent Scatterers Technology: A Powerful State of the art Tool for Historic and Future Monitoring of Landslides and Other Terrain Instability Phenomena. In Proceedings of the International landslide Symposium-ISL2005, London, UK, 31 May-3 June 2005.

47. Ferretti, A.; Savio, G.; Barzaghi, R.; Borghi, A.; Musazzi, S.; Novali, F.; Prati, C.; Rocca, F. Submillimeter Accuracy of InSAR Time Series:Experimental Validation. IEEETrans. Geosci. Remote Sens. 2007, 45, 1142-1153. [CrossRef] 
48. Lauknes, T.R.; Dehls, J.; Larsen, Y.; Høgda, K.A.; Weydahl, D.J. Acomparison of SBAS and PSERSInSAR for subsidence monitoring inOslo, Norway. In Proceedings of the Fringe 2005 Workshop, ESA ESRIN, Frascati, Italy, 28 November-2 December 2005.

49. Hooper, A. Persistent Scatterer Radar Interferometry for Crustal Deformation Studies and Modeling of Volcanic Deformation. Ph.D. Thesis, Stanford University, Stanford, CA, USA, 2006.

50. Zhou, W.; Chen, G.; Li, S.; Ke, J. InSAR Application in Detection of Oilfield Subsidence on Alaska North Slope. In Proceedings of the 41st US Symposiumon Rock Mechanics (USRMS), Golden, CO, USA, 17-21 June 2006. 